\title{
Distributions of stress-resistant coral symbionts match environmental patterns at local but not regional scales
}

\author{
Thomas A. Oliver*, Stephen R. Palumbi \\ Department of Biological Sciences, Hopkins Marine Station, Stanford University, 120 Oceanview Boulevard, \\ Pacific Grove, California 93950, USA
}

\begin{abstract}
Distribution patterns of stress-tolerant coral symbionts suggest that maximum habitat temperatures can drive local scale adaptation of symbiont populations, but at regional scales other processes can dominate. We assayed clade membership for symbionts of 2 closely related corals from American Samoa, Fiji, the Philippines and Palmyra Atoll. Temperature stress-tolerant Clade D symbionts occur more frequently in American Samoa (83\%) than in Palmyra, Fiji or the Philippines $(<1 \%)$. In American Samoa, Clade D symbionts dominate habitats with higher maximum temperatures, while Clades C and D are both common under lower maximum temperatures. While corals in American Samoa show more stress-tolerant symbionts, this region does not exhibit higher sea surface temperatures, a greater record of heating anomalies or more bleaching than the other 3 regions. That these local patterns do not hold regionally suggests the importance of other factors, including host responses, other environmental correlates, within-clade physiological diversity and dispersal limitation, in driving the distribution of coral symbionts.
\end{abstract}

KEY WORDS: Coral reefs $\cdot$ Climate change $\cdot$ Adaptation $\cdot$ Acropora $\cdot$ Symbiodinium $\cdot$ Cytochrome $b$. High temperature stress

Resale or republication not permitted without written consent of the publisher

\section{INTRODUCTION}

Coral bleaching involves the breakdown of the symbiosis between reef-building corals and their obligate endosymbionts, dinoflagellates in the genus Symbiodinium. While bleaching can be triggered by a range of stimuli, mass bleaching events are most commonly induced by a synergistic effect between temperature and light (Fitt et al. 2001). Even an increase as small as $1{ }^{\circ} \mathrm{C}$ above long-term maximum temperatures can trigger bleaching (Goreau \& Hayes 1994). With projected warming trends due to global climate change (Bindoff et al. 2007, Meehl et al. 2007), corals will most likely be routinely exposed to physiological stress unless they can adapt to increased temperatures (Hoegh-Guldberg 1999, Hughes et al. 2003).

Many observational and experimental studies suggest that not all coral-Symbiodinium combinations react equally to bleaching-inducing stresses; therefore, variability exists upon which natural selection may act (Rowan et al. 1997, Rowan 2004, Berkelmans \& van Oppen 2006). For example, Rowan et al. (1997) observed that, within a single coral colony, regions of the colony hosting Symbiodinium symbionts in Clade C might bleach, while those hosting Clades A or B might not.

Similar observations have been made in Pacific corals. Before, during and after the 1998 bleaching event, Glynn et al. (2001) sampled Pocillopora damicornis in Pacific Panama. They noted that each of the 9 coral colonies sampled that hosted Clade C Symbiodinium bleached during the thermal stress, while none of the 33 that hosted Clade D bleached. Also, the frequency of Clade D Symbiodinium increased after the bleaching event (Baker et al. 2004).

Experimental work has followed up on these observations. Working with Pocillopora verrucosa from Guam, Rowan (2004) placed colonies bearing either Clade C or D Symbiodinium into tanks held at either 
control $\left(28.5^{\circ} \mathrm{C}\right)$ or elevated temperatures (31.3 or $32.0^{\circ} \mathrm{C}$ ). Colonies hosting Clade C Symbiodinium in the $32.0^{\circ} \mathrm{C}$ treatment showed evidence of heatinduced damage to the light reactions of photosynthesis, while those hosting Clade D Symbiodinium did not. Rowan (2004) concluded that Clades C and D are adapted to different thermal regimes, and Clade D appears to be a high temperature specialist.

The increased thermal robustness provided by hosting Clade D may incur some cost to the coral. Little et al. (2004) documented that juvenile Acropora tenuis and A. millepora hosting Clade D Symbiodinium grew at half the rate of those hosting Clade $\mathrm{C}$ at the same site. This is the only published example of a trade-off for Clade D thermal resistance, and it remains unknown if the growth limitations apply to A. tenuis and A. millepora adults and/or other species.

Although some coral species host multiple symbiont types, others appear to host only a single type. Species in the genus Porites primarily associate with a single symbiont type (LaJeunesse et al. 2004, Thornhill et al. 2006a), while many species in the genera Acropora and Pocillopora commonly host multiple clades of Symbiodinium (van Oppen et al. 2001, Baker 2003, LaJeunesse et al. 2004). The proportion of scleractinian corals that can host multiple symbionts has been recently debated (Goulet 2006, Baker \& Romanski 2007), but estimates using adequate sample sizes ( $\mathrm{n}>5$ samples per species) suggest that at least $58 \%(72 / 124)$ of the species examined hosted more than one clade of symbiont (Baker \& Romanski 2007). Even among those capable of hosting multiple symbionts, long-term monitoring studies have shown that without environmental perturbation, symbiont communities show little change over time (Thornhill et al. 2006b). However, multiple studies have shown rapid shifts in Symbiodinium communities following environmental perturbation (Baker et al. 2004, Thornhill et al. 2006b, Jones et al. 2008, LaJeunesse et al. 2008).

Because many coral species have the potential to host physiologically distinct symbionts (Baker 2003, Goulet 2006, Baker \& Romanski 2007), much attention has focused on the potential for corals to raise their thermal tolerances by increasing the occurrence of stress-resistant Symbiodinium lineages (Buddemeier \& Fautin 1993, Baker 2001, Baker et al. 2004, Berkelmans \& van Oppen 2006, Jones et al. 2008). As originally proposed in the adaptive bleaching hypothesis, adult corals replace stress-susceptible symbionts with stressresistant symbionts to match a stressful environment (Buddemeier \& Fautin 1993). The pattern of occurrence of stress-tolerant symbionts could be produced either by adults shifting their symbionts, new generations of corals preferentially acquiring resistant symbionts, or those corals bearing sensitive symbionts suffering differential mortality (Jones et al. 2008).
These studies (Buddemeier \& Fautin 1993, Baker et al. 2004, Rowan 2004, Berkelmans \& van Oppen 2006, Jones et al. 2008) strongly suggest that for corals able to support both Clades C and D there should be a relationship between the thermal environment of a coral population and its frequency of Clade C vs. D Symbiodinium. However, no studies to date have provided a definitive answer to this question. Most studies that have attempted to build a predictive relationship between Symbiodinium genotypes and their environments have focused on a local scale (Rowan et al. 1997, Glynn et al. 2001, Toller et al. 2001, Baker 2003, Chen et al. 2003), and the few studies that have attempted to draw general patterns on a regional scale have yet to return a definite set of environmental variables which predict Symbiodinium distributions (Baker et al. 2004, Garren et al. 2006, Lien et al. 2007).

Baker et al. (2004) compared patterns of Symbiodinium distribution from multiple coral hosts across regions ranging from cool, relatively unbleached Mauritius to the hotter and more bleached sites of Kenya, the Red Sea and the Persian Gulf. They concluded that the high proportion of Clade D in 2 of the 3 hotter regions suggests that reef-scale shifts to Clade D Symbiodinium is a common feature among reef corals globally (Baker et al. 2004). In their comparison of Panamanian and Belizian Montastrea annularis (sensu lato) populations, Garren et al. (2006) demonstrated that the Symbiodinium community compositions were more strongly correlated to region than the environmental variables at each site. Lien et al. (2007) examined the coral Ouleastrea crispata, which hosts Clade D almost exclusively. Of their 100 samples, they only found 4 instances of a coral hosting Clade $\mathrm{C}$, all of which were in hotter, tropical regions (Lien et al. 2007).

Each of these studies (Baker et al. 2004, Garren et al. 2006, Lien et al. 2007) has a fundamental issue that obscures its ability to draw general conclusions about how environmental factors drive the distribution of Symbiodinium genotypes. Baker et al. (2004) sampled a different set of coral hosts in each region and did not address the existence of resistant strains outside of Clade D. Garren et al. (2006) only sampled from 2 regions, and used single time points to characterize site temperatures. Lein et al. (2007) focused on a minor member of reef communities that appears to have an atypically specific relationship to Clade D Symbiodinum.

To address these issues, we sampled from a consistent set of coral hosts at consistently shallow depths across multiple spatial scales and among multiple regions using time series environmental data. We surveyed a bleaching-susceptible pair of corals in the genus Acropora, a genus known as a major component of Pacific reefs with species known to host Clades C 
and D (T. A. Oliver \& S. R. Palumbi unpubl. data). We sampled A. hyacinthus and A. cytherea for their Symbiodinium clade at 2 spatial scales: across the equatorial Pacific Ocean from the Philippines to Palmyra Atoll, and at a local scale contrasting inner reef and outer reef sites in American Samoa. These data confirm Baker et al.'s (2004) model that high temperatures affect the distribution of Symbiodinium on the local scale. However, the patterns appear to break down on a regional scale; data on heating history and bleaching across the Pacific suggest that the complexities of coral-Symbiodinium adaptation likely go beyond temperature and bleaching history.

\section{MATERIALS AND METHODS}

Sampling. Between May 2005 and August 2006 we sampled sister species of table-top Acroporid corals, Acropora hyacinthus and A. cytherea, in 3 regions of the Pacific-Palmyra Atoll, the central Philippines and Fiji, and sampled A. hyacinthus in American Samoa (Table 1). In American Samoa, we explicitly sampled across habitat boundaries in 3 sites, sampling corals from 1 to $7 \mathrm{~m}$ deep from both thermally variable backreef environments and the nearby fore-reef in each site. In Ofu Island, American Samoa, we sampled from 3 back-reef pools that we refer to as Pool 300, 400 and
500. In Palmyra Atoll, the Philippines and Fiji we sampled from a range of shallow water habitats (1 to $5 \mathrm{~m}$ ), including back-reef and fore reef-environments. In all cases, we sampled coral colonies separated by 10 to 30 $\mathrm{m}$ to minimize multiple samplings from a single ramet. Branchlets measuring $\sim 1 \mathrm{~cm}$ long were preserved in $70 \%$ ethyl alcohol (EtOH) at room temperature (Table 1).

Molecular characterization and significance testing. All Symbiodinium samples were assigned to a specific clade using $351 \mathrm{bp}$ of mitochondrial Cytochrome $b$ (Table 2). Post-PCR, the samples were cleaned with exonuclease and shrimp alkaline phosphatase (NEB) and cycle-sequenced using BigDye dideoxy sequencing chemistry (Applied Biosystems). Labelled samples were ethanol-precipitated and capillary-sequenced on an ABI 3100 (Applied Biosystems).

After sequencing, we assigned each sample a clade distinction as A, C, D or C' (found only in Fiji). We then performed chi-square tests of the resulting clade frequencies to distinguish between regions, habitats or back-reef pools.

Genetically distinct Symbiodinium can exist in a single sample (van Oppen et al. 2001), but knowing the electropharograms of these distinct types in isolation, we could easily distinguish a mixed electropharogram. In samples exhibiting a mixed signal, we counted their contributions as half an instance for each clade.

Table 1. Sampling locations, habitat description and number of Acropora hyacinthus and A. cytherea samples collected

\begin{tabular}{|c|c|c|c|c|c|c|c|}
\hline Site & Latitude & Longitude & Habitat (depth) & A. hyacinthus & A. cytherea & $\begin{array}{l}\text { A. hyacinthus/ } \\
\text { A. cytherea }\end{array}$ & $\begin{array}{c}\text { Regional } \\
\text { totals }\end{array}$ \\
\hline \multicolumn{8}{|l|}{ American Samoa } \\
\hline \multirow[t]{2}{*}{ Ofu Island } & $14.169^{\circ} \mathrm{S}$ & $169.665^{\circ} \mathrm{W}$ & Back-reef $(1-3 \mathrm{~m})$ & 24 & 0 & & \\
\hline & & & Fore-reef $(2-7 \mathrm{~m})$ & 24 & 0 & & \\
\hline \multirow[t]{2}{*}{ Vatia Bay } & $14.272^{\circ} \mathrm{S}$ & $170.628^{\circ} \mathrm{W}$ & Back-reef $(1-4 \mathrm{~m})$ & 24 & 0 & & \\
\hline & & & Fore-reef $(1-4 \mathrm{~m})$ & 23 & 0 & & \\
\hline \multirow[t]{2}{*}{ Faga'itua Bay } & $14.254^{\circ} \mathrm{S}$ & $170.615^{\circ} \mathrm{W}$ & Back-reef (1-3 m) & 23 & 0 & & \\
\hline & & & Fore-reef $(1-4 \mathrm{~m})$ & 24 & 0 & & 142 \\
\hline \multicolumn{8}{|l|}{ Fiji } \\
\hline Bounty Island & $17.670^{\circ} \mathrm{S}$ & $177.302^{\circ} \mathrm{E}$ & $(1-5 \mathrm{~m})$ & 18 & 12 & & \\
\hline Maui Bay & $18.217^{\circ} \mathrm{S}$ & $177.717^{\circ} \mathrm{E}$ & $(1-5 \mathrm{~m})$ & 6 & 0 & & \\
\hline Makagai Island & $17.447^{\circ} \mathrm{S}$ & $178.946^{\circ} \mathrm{E}$ & $(1-5 \mathrm{~m})$ & 4 & 0 & & \\
\hline Naigani Island & $17.579^{\circ} \mathrm{S}$ & $178.676^{\circ} \mathrm{E}$ & $(1-5 \mathrm{~m})$ & 11 & 10 & & \\
\hline Votua & $16.624^{\circ} \mathrm{S}$ & $178.723^{\circ} \mathrm{E}$ & $(1-5 \mathrm{~m})$ & 26 & 1 & & 88 \\
\hline \multicolumn{8}{|l|}{ Philippines } \\
\hline Bacuit Bay, South Maniloc & $11.087^{\circ} \mathrm{N}$ & $119.397^{\circ} \mathrm{E}$ & $(1-5 \mathrm{~m})$ & 3 & 3 & & \\
\hline Coron Bay, San Gat & $11.981^{\circ} \mathrm{N}$ & $120.062^{\circ} \mathrm{E}$ & $(1-5 \mathrm{~m})$ & 8 & 10 & & \\
\hline Coron Bay, Dynamite Pt. & $11.920^{\circ} \mathrm{N}$ & $120.027^{\circ} \mathrm{E}$ & $(1-5 \mathrm{~m})$ & 4 & 9 & 1 & 38 \\
\hline \multicolumn{8}{|l|}{ Palmyra Atoll } \\
\hline Penguin Spit & $5.871^{\circ} \mathrm{N}$ & $162.101^{\circ} \mathrm{W}$ & $(1-4 \mathrm{~m})$ & 23 & 18 & & 41 \\
\hline
\end{tabular}


Table 2. PCR primers and reaction conditions used in the molecular characterization of Symbiodinium samples. Init. denat.: inital denaturation temperature and time; Denat.: denaturation temperature and time; Ext.: extention temperature and time; Final ext.: final extention temperature and time. Temperatures and times apply separately to the DinoCob1 primer pair and the CytbF/R primer pair

\begin{tabular}{|c|c|c|c|c|c|c|c|c|c|}
\hline Locus & Primer & Primer sequence $\left(5^{\prime} \rightarrow 3^{\prime}\right)$ & Init. denat. & Denat. & Anneal & Ext. & Final ext. & No. cycles & Source \\
\hline \multirow[t]{4}{*}{$\begin{array}{l}\text { Cyto- } \\
\text { chrome } b\end{array}$} & DinoCob1-f & $\begin{array}{l}\text { ATG AAA TCT CAT TTA } \\
\text { CAW WCA TAT CCT TGT CC }\end{array}$ & $94^{\circ} \mathrm{C}$ & $94^{\circ} \mathrm{C}$ & $55^{\circ} \mathrm{C}$ & $72^{\circ} \mathrm{C}$ & $72^{\circ} \mathrm{C}$ & $30-40$ & $\begin{array}{l}\text { Zhang et } \\
\text { al. (2005) }\end{array}$ \\
\hline & DinoCob1-r & $\begin{array}{l}\text { TCT CTT GAG GKA ATT } \\
\text { GWK MAC CTA TCC A }\end{array}$ & $1 \mathrm{~min}$ & $20 \mathrm{~s}$ & $30 \mathrm{~s}$ & $30 \mathrm{~s}$ & $10 \mathrm{~min}$ & & \\
\hline & CytbF1 & $\begin{array}{l}\text { TTA TCT GGA TGT GAG AAA } \\
\text { GAA GAG AAA CC }\end{array}$ & $94^{\circ} \mathrm{C}$ & $94^{\circ} \mathrm{C}$ & $55^{\circ} \mathrm{C}$ & $72^{\circ} \mathrm{C}$ & $72^{\circ} \mathrm{C}$ & $30-40$ & $\begin{array}{l}\text { Present } \\
\text { study }\end{array}$ \\
\hline & CytbR2 & $\begin{array}{l}\text { CCA TTC AGG TAC TAT ATG } \\
\text { TAA AGG AGT AAG }\end{array}$ & $3 \mathrm{~min}$ & $30 \mathrm{~s}$ & $30 \mathrm{~s}$ & $30 \mathrm{~s}$ & $5 \min$ & & \\
\hline
\end{tabular}

Temperature records. In situ: To compare thermal environments in the distinct habitats sampled in American Samoa, we placed temperature loggers in both back-reef and fore-reef environments. In Vatia Bay we deployed 2 LOTEK archival tags (LTD-2310), one in the fore-reef and one in the back-reef. These tags collected temperature data with a $30 \mathrm{~s}$ sampling interval and $0.05^{\circ} \mathrm{C}$ temperature resolution. In Faga'itua Bay, we deployed 4 I-buttons (DS1921G, Dallas Semiconductor), 2 in the fore-reef and 2 in the back-reef. These smaller data loggers collected a temperature data point every $20 \mathrm{~min}$ with a resolution of $0.5^{\circ} \mathrm{C}$. Data loggers in both Vatia and Faga'itua Bays sampled from 12 March to 2 April 2006.

The National Park Service has collected temperature records from Ofu Island since 1999. Ofu temperatures were recorded using 4 Hobo Temp loggers (U22-001) with a 30 min sampling interval and $0.02^{\circ} \mathrm{C}$ temperature resolution. Three were placed in separate pools in the back-reef, and 1 on the fore-reef at Sili.

We selected only those measurements that occurred within the sampling period of 12 March through 2 April 2006. For sites with multiple loggers in a habitat, we pooled measurements across these loggers into a single distribution. Because we lack 2006 measurements from Ofu Island's fore-reef, we have plotted data from the same $21 \mathrm{~d}$ in 2005.

Remotely sensed sea surface temperature. To compare temperatures between the 4 regions, we used $8 \mathrm{~d}$ composite sea surface temperature (SST) data from NOAA's Pathfinder v5 satellite. We extracted SST data from a $2^{\circ}$ square area around each region. The reported temperature for a given measurement period is the mean of all measurements within the area. The data cover 1998 to 2006. Temperatures presented are the overall mean, the mean of the maximum $5 \%$, and the mean of the minimum $5 \%$, with associated SD.

Degree heating week analyses. To compare histories of heating anomalies across the 4 regions, we em- ployed NOAA's measure of degree heating weeks (DHW). These values are a measure of both how extreme a heating anomaly is and how long it lasts. SST data from 1985 to 1994 were used to set the long-term baseline, with the exclusion of 1991 and 1992 due to Mt. Pinatubo's eruption. From this baseline dataset, NOAA derived mean hottest summer temperatures by selecting the maximum temperature from the longterm mean of each month in the year. Temperatures in excess of this long-term threshold are taken to be temperature anomalies, and logged as NOAA HotSpots. The measure of a DHW comes from the product of the how far the temperature is above the threshold (in ${ }^{\circ} \mathrm{C}$ ) and the length of time the temperature has been above that threshold in weeks (Morgan et al. 2006). Raw data for DHW values are available from NOAA's National Climate Data Center covering December 2000 to present. Values from March 1998 to December 2000 were taken directly from images from NOAA's National Climate Data Center (NOAA 2007).

Each value in the DHW time series for a given region is the mean of a $2^{\circ}$ square centered on the region. Total DHW data were calculated as the numerical integration of the DHW time series by summing the product of a measured DHW value and the time interval until the next sample.

Bleaching records. A database of bleaching reports exists at the online reef information center, ReefBase (www.reefbase.org). The source of these reports ranges from peer-reviewed publications, grey literature, to personal observations submitted to the website. All reports have been characterized by location, date and scale of bleaching from zero to 3 , where zero is no bleaching, one is 1 to $10 \%$ of colonies on a reef bleached, 2 is 10 to $30 \%$ of colonies bleached and 3 is $>30 \%$ colonies bleached.

We took all the records belonging to one of the 4 regions of interest (American Samoa, Philippines, Fiji 
and Palmyra Atoll) and then calculated both the mean and SE of the 0-3 scale of bleaching intensity. Error bars represent SE of bleaching intensity.

\section{RESULTS}

\section{Genetic diversity}

For the 309 Symbiodinium samples that we generated we found 4 distinct sequences at Cytochrome b: 2 Clade $\mathrm{C}$ genotypes, 1 Clade A genotype and 1 Clade D genotype. One Clade C genotype was shared across all populations (186 instances) and one was specific to Fiji (5 instances). Both Clade A and D genotypes were restricted to American Samoa (A: 1 instance, D: 117 instances). At cytochrome $b$, Clades C and D were separated by $2.53 \%$ (Kimura 2 parameter distance) with 20 single nucleotide polymorphisms, 16 of which were non-synonymous. An indicator of the degree of positive selection, the whole sequence Dn/Ds value, for this comparison is 1.18 .

\section{Genetic comparisons}

Although the heat-resistant Clade D Symbiodinium made up $82.4 \%$ of the 142 samples from American Samoa, we did not find a single sample hosting Clade D from Fiji $(\mathrm{n}=88)$, Palmyra Atoll ( $\mathrm{n}=41)$, or the central Philippines $(\mathrm{n}=31)$ in either Acropora hyacinthus or A. cytherea. Clade C in American Samoa, Palmyra Atoll, and the Philippines across both coral species showed the same haplotype for the $351 \mathrm{bp}$ of cytochrome $b$ sequenced. Clade $\mathrm{C}$ in Fiji showed both the haplotype found elsewhere $(n=83)$ and a subtype of Clade $C\left(C^{\prime}\right)(n=5)$ that differed from the other $C$ by 2 substitutions at cytochrome $b$ (Fig. 1a).

In contrast, we commonly found Symbiodinium Clades C and D in American Samoa. We also found one instance of Clade A Symbiodinium on the backreef of Faga'itua. Overall the Symbiodinium community hosted by Acropora hyacinthus was comprised of 82.4\% Clade D, $16.9 \%$ Clade C and $0.7 \%$ Clade A. A. cytherea were not sampled in American Samoa.

Shifts in the frequencies of genotypes of Symbiodinium hosted by Acropora hyacinthus occurred across habitats. In both Vatia and Faga'itua Bays, Clade C was

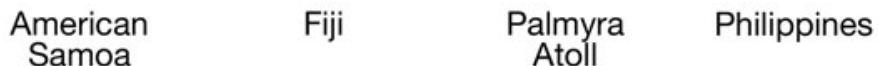
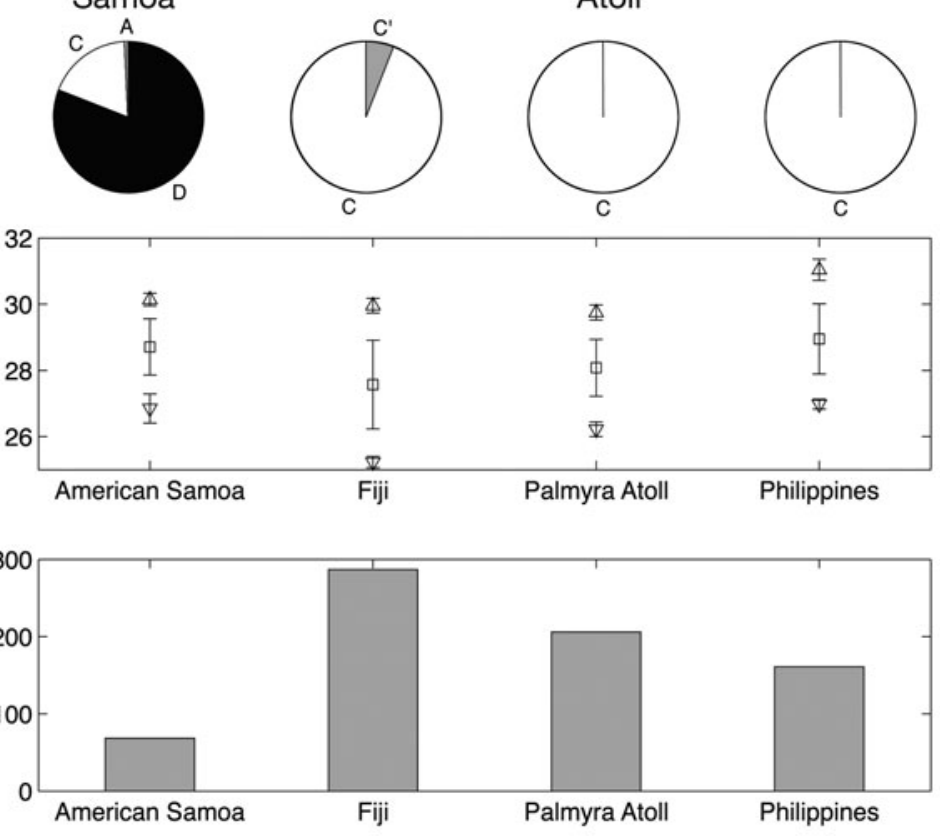

Fig. 1. Regional Symbiodinium sp. clade frequencies and environmental characterizations. (A) Symbiodinium sp. clade frequencies by region; white: Clade C; light grey: Clade $A_{\text {; }}$ black: Clade $D_{\text {; }}$ medium grey: Clade C. (B) maximum $5 \%(\Delta)$, gree heating weeks (DHW) from integrating 1998-2006 time series by region; and (D) mean annual bleaching severity by region, 1994-2006. Error bars are $\pm \mathrm{SD}$

absent from the back-reef habitats in which Clade D dominated. However, on the nearby fore-reefs, Clade C reached 37 and $21 \%$, respectively. The shifting frequencies of Clade $\mathrm{C}$ and $\mathrm{D}$ across the fore-reef/back-reef divide were significant at both sites $\left(\chi^{2}, p=0.0008,0.041\right.$ for Vatia and Faga'itua Bays, respectively) (Fig. 2A).

At Ofu Island, back-reef frequencies of Clade C were lower than fore-reef frequencies, but not significantly so, with $19 \% \mathrm{C}$ in the back-reef and $27 \%$ in the fore-reef (Fig. 2A). However, within the back-reef on Ofu we found exclusively Clade D in Pool 300, the pool with the largest swings in temperature (see 'Environmental comparisons'). We found clustered groups of Clade C within Pools 400 and 500, back-reef environments that more closely approximate fore-reef conditions (Fig. 2B). This back-reef structuring of $\mathrm{C}$ and $\mathrm{D}$ genotypes was not statistically significant due to the small numbers of table-top coral colonies available for 

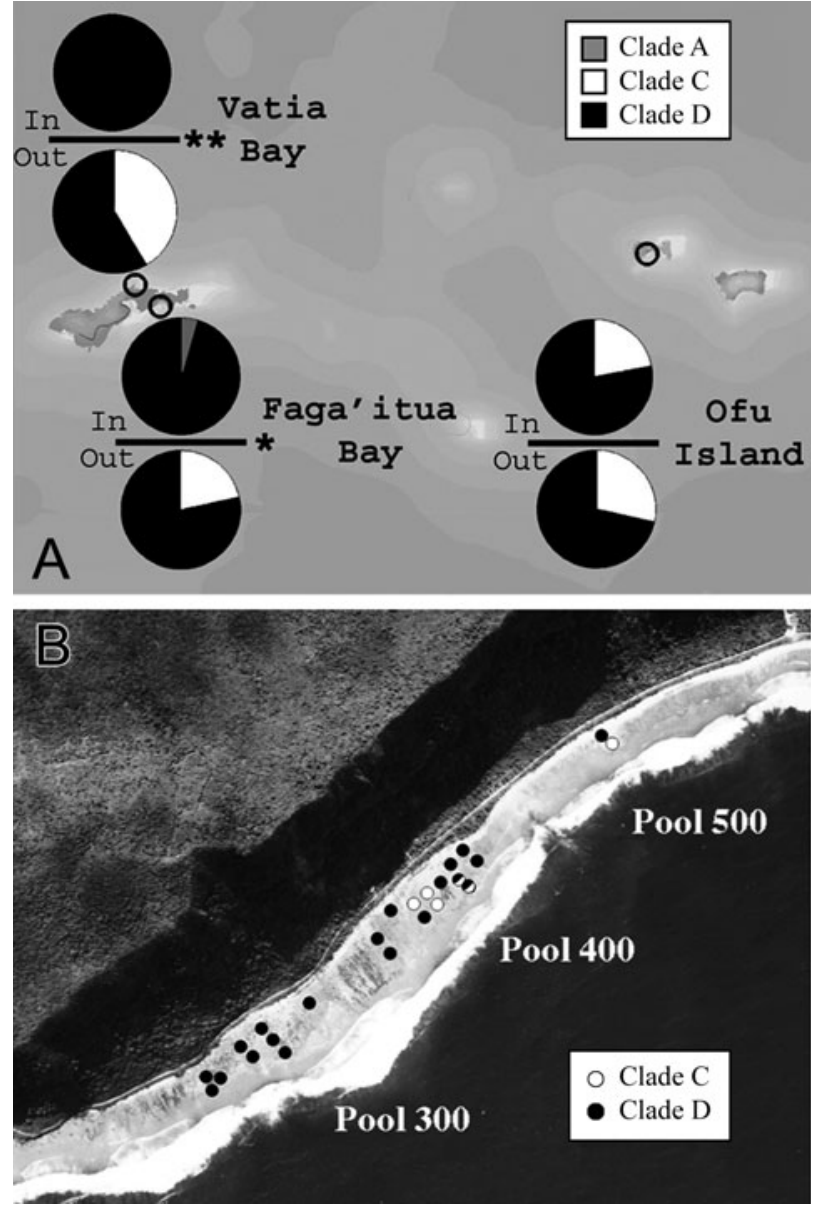

Fig. 2. Symbiodinium sp. clade designations in American Samoa. (A) Clade designations of Symbiodinium sp. from populations of Acropora hyacinthus in the back-reefs and fore-reefs in 3 bays. In: back-reef populations; Out: fore-reef populations. Chi-square comparison of 'In' to 'Out' clade distributions: Vatia Bay, $\mathrm{p}=0.0008\left({ }^{* *}\right)$; Fagai'tua Bay, $\mathrm{p}=0.041$ $\left({ }^{*}\right)$; and Ofu Island, not significant. (B) Clade designations of individual colonies of $A$. hyacinthus in back-reef pools in Ofu Island. Half-filled circles: mixed clade signatures

analysis $\left(\chi^{2}, \mathrm{p}=0.068\right)$, but it does qualitatively match the patterns seen across habitats in other sites, in which corals were dominated by Clade D in the most thermally extreme habitats and hosted either C or D in the more thermally moderate habitats.

\section{Environmental comparisons}

American Samoa temperature records

We compared temperatures from Ofu Island, Vatia Bay and Faga'itua Bay in both fore-reef and back-reef habitats (Fig. 3A-C). Across the 3 sites, mean temperatures across habitats differed only slightly, while maximum temperatures ranged from 0.95 to $2.2^{\circ} \mathrm{C}$ higher and minimum temperatures ranged from 0.59 to $1.17^{\circ} \mathrm{C}$ lower in the back-reef. The average variance of the temperature distributions across all back-reef sites (variance $=0.24$ ) was $>2.5$ times higher than that of all fore-reef sites (variance $=0.089$ ).

In Ofu Island, we found similar variation between discrete pools on the back-reef. One of 3 pools monitored (Pool 300) showed high thermal variability while the other 2 (400 and 500) were more moderate in their temperature swings (Fig. 3). If we restrict our analysis to the $3 \mathrm{wk}$ analyzed for other sites, we find that maximum temperatures from Pool 300 were $1.5^{\circ} \mathrm{C}$ hotter than those from Pools 400 and 500, and minimum temperatures from Pool 300 were $0.92^{\circ} \mathrm{C}$ cooler than those from Pools 400 and 500. The temperature distributions also show differences in their variances. Pool 300's variance wss 0.49 , while those of Pools 400 and 500 were 3 to 5 times lower ( 0.17 and 0.094 , respectively). If we expand our analysis to the entire $6.5 \mathrm{yr}$ temperature record from these pools, the differences between the habitats increase but the results do not qualitatively change. Thus, Pool 300 showed a temperature profile similar to back-reef environments elsewhere in American Samoa, while Pools 400 and 500 were more similar to fore-reef environments.

\section{Regional mean, maximum and minimum SST}

Based on regional satellite-derived mean, maximum and minimum SST, American Samoa was slightly warmer than both Fiji and Palmyra, but the Philippines were consistently warmer than all other locations sampled (Table 3, Fig. 1B).

\section{Anomalous heating events}

Regional temperatures themselves may not be the best measure of a region's history of bleaching stress. Potentially more relevant are the frequency, severity and duration of anomalous heating events. Soon after the 1998 El Niño bleaching events, NOAA developed an index to measure such events, the DHW. From 1998 to 2006, American Samoa showed 68.3 DHWs compared to 286.7 in Fiji, 160.9 in Palmyra and 206 in the Philippines (Fig. 1C).

\section{Bleaching events}

The bleaching event data demonstrate that American Samoa has not suffered an atypically high degree of bleaching. While American Samoa has bleached re- 

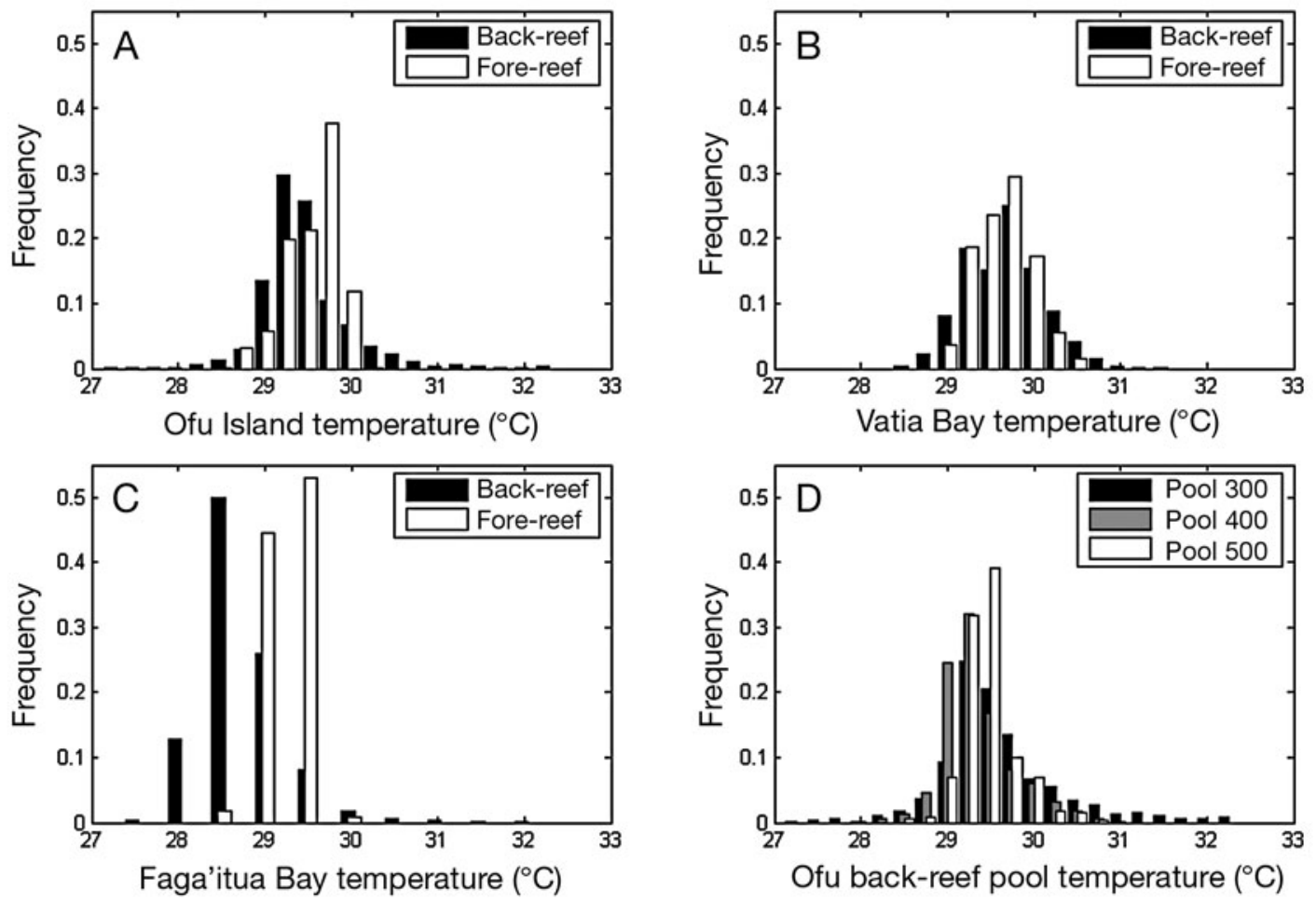

Fig. 3. In situ temperature measurements from American Samoa. Fore-reef and back-reef distributions from (A) Ofu Island, (B) Vatia Bay and (C) Faga'itua Bay. (D) In situ temperature distributions from 3 back-reef pools in Ofu Island

Table 3. Regional environmental characterizations $( \pm \mathrm{SD})$, including mean, maximum and minimum sea surface temperatures (SST), total number of degree heating weeks (DHW), annual mean bleaching severity (see 'Materials and methods' for description of scale), and number of bleaching reports

\begin{tabular}{|c|c|c|c|c|c|c|}
\hline Region & $\begin{array}{c}\text { Mean SST } \\
\left({ }^{\circ} \mathrm{C}\right)\end{array}$ & $\begin{array}{c}\text { Max. } 5 \% \text { SST } \\
\left({ }^{\circ} \mathrm{C}\right)\end{array}$ & $\begin{array}{c}\text { Min. }>5 \% \text { SST } \\
\left({ }^{\circ} \mathrm{C}\right)\end{array}$ & $\begin{array}{l}\text { Total } \\
\text { DHW }\end{array}$ & $\begin{array}{c}\text { Annual mean } \\
\text { bleaching severity } \\
(0-3)\end{array}$ & $\begin{array}{l}\text { No. bleaching } \\
\text { reports }\end{array}$ \\
\hline American Samoa & $28.71 \pm 0.85$ & $30.14 \pm 0.19$ & $26.85 \pm 0.44$ & 68.27 & $1.10 \pm 0.59$ & 39 \\
\hline Fiji & $27.57 \pm 1.34$ & $29.96 \pm 0.22$ & $25.23 \pm 0.17$ & 286.74 & $2.33 \pm 0.90$ & 45 \\
\hline Palymra Atoll & $28.08 \pm 0.86$ & $29.75 \pm 0.23$ & $26.22 \pm 0.22$ & 205.97 & $1.25 \pm 1.26$ & 66 \\
\hline Philippines & $28.95 \pm 1.06$ & $31.04 \pm 0.32$ & $26.98 \pm 0.15$ & 160.9 & $2.28 \pm 0.75$ & 4 \\
\hline
\end{tabular}

peatedly in the past $9 \mathrm{yr}$, the events have been limited in scope with an average annual bleaching index of 1.25 out of 3 , or slightly $>10 \%$ of the reef bleached. Fiji and the Philippines showed repeated severe bleaching events which raised the average annual bleaching index values to 1.92 and 2.32, respectively. The data record from Palmyra Atoll suffers from severe underreporting due to its remote location. Over the period of time in which we have 39, 45 and 66 bleaching reports from American Samoa, Fiji and the Philippines, only 4 reports exist from Palmyra Atoll. With the exception of 1998, no reports exist from periods during or directly after the major DHW anomalies, so under-reporting is likely to underestimate bleaching severity. Even so, the average annual bleaching index over the past $9 \mathrm{yr}$ is 1.33, slightly higher than that of American Samoa (Fig. 1D).

\section{Environmental-symbiont correlations}

In American Samoa we found clear associations between Symbiodinium genotype and thermal regime in a given habitat. At 2 sites, Faga'itua and Vatia Bays, Clade D dominated back-reef habitats to the exclusion of Clade C. These back-reef habitats had both higher temperature maxima and variability in comparison to the cooler and more constant fore-reef where we saw Clade $\mathrm{C}$ in substantial proportions.

The correlations between environmental temperature regime and Symbiodinium genotype found at the local scale in American Samoa were not maintained in our analysis at the regional scale. No Clade D Symbiodinium was found outside of American Samoa, but American Samoa was no hotter than Fiji or Palmyra 
Atoll and was cooler than the Philippines. Of the 4 regions, American Samoa showed the lowest number of bleaching-relevant temperature anomalies and an equal or lesser number of bleaching events.

\section{DISCUSSION}

Our data show that, at a local scale, sites with higher maximum temperatures had higher proportions of stress-tolerant symbionts. However, this relationship does not appear to hold at larger scales across the Pacific. In the table-top Acroporid corals, frequency shifts between Clade C and Clade D Symbiodinium across habitats in American Samoa correlated with shifts in the habitats' thermal regime, with the more stress-resistant Clade D dominating the habitats with higher maximum temperatures. While sampled corals from American Samoa were dominated by Clade D symbionts, samples from Fiji, Palmyra Atoll and the Philippines only showed symbiont Clade C. Contrary to expected patterns, American Samoa did not stand out as an outlier in either its thermal environment or bleaching history.

\section{American Samoa: clade frequency differences among habitats}

Previous studies of Clade D Symbiodinium have demonstrated its potential role in resisting the negative effects of elevated temperatures on the coral-algal symbiosis (Glynn et al. 2001, Rowan 2004, Berkelmans \& van Oppen 2006). In American Samoa, we observed that Clade D Symbiodinium were more common in back-reef habitats that reach high maximum temperatures than in nearby habitats with more moderate thermal environments (e.g. fore-reef). The observed association between Symbiodinium genotype and thermal habitat suggests that populations of Acropora hyacinthus in more thermally extreme habitats in American Samoa have matched their local environment by hosting a more heatresistant symbiont. On the fore-reef, corals may not require the thermal tolerance provided by Clade D and may grow faster with Clade $\mathrm{C}$ symbionts. This trade-off has been demonstrated in juvenile $A$. tenuis (Little et al. 2004). Whether the same trade-off applies to different coral species (e.g. A. hyacinthus), adult corals or other locations is not yet known.

\section{Regional comparisons}

Although Clade D is common in American Samoa (83\% of all samples), extensive sampling in Fiji, Pal- myra Atoll and the Philippines revealed only Clade C Symbiodinium (Fig. 1A). If the same adaptive processes acting on a local scale in American Samoa are driving distributions of Clades $\mathrm{C}$ and $\mathrm{D}$ on a regional scale, we would expect regional patterns to match local patterns. That is, Clade D would appear in regions with a greater history of temperature extremes, abnormal heating events or coral bleaching.

Contrary to these predictions, the warmest regions with the highest bleaching histories had very low levels of Clade D. In addition, American Samoa did not appear to be an environmental outlier among the populations examined (Fig. 1B-D). It had an equal or lower bleaching history, lower record of high temperature anomalies and was intermediate with regard to temperature. From this we conclude that the environmental variables examined at the regional scale have poor predictive power to distinguish between American Samoa, with its high incidence of Clade D, and Fiji, Palmyra Atoll and the Philippines, with no Clade D.

\section{Alternative hypotheses}

Our results suggest that while adaptation to temperature and bleaching history may play a role, there are other processes involved in the distribution patterns of Symbiodinium across the Pacific. Because the focal species of the present study can host both Clades C and D, host-symbiont specificity is unlikely to be an important factor. The failure of the strict environmental model to predict the proportion of resistant symbionts outside of American Samoa leads us to address other potential hypotheses: (1) coral adaptation, (2) unexamined environmental variables, (3) cryptic stress tolerance and (4) dispersal limitation.

\section{Coral adaptation}

There may be other mechanisms of stress tolerance occurring at the level of the coral host that are critical outside American Samoa. Researchers have documented variation in bleaching sensitivity across distinct coral species (McClanahan et al. 2001, 2007), and 2 studies have seen differences in thermal tolerance among members of a coral species that could be due to genetic differences (Smith-Keune \& van Oppen 2006, Ulstrup et al. 2006). However, no study has yet linked variation in thermal sensitivity to specific genetic differences among corals. If corals themselves can adapt or acclimate to higher temperature, they may be able to survive environmental change without sacrificing 
the potential growth disadvantage shown for Symbiodinium Clade D.

Unexamined environmental variables

It is possible that other, unexamined environmental variables determine Clade D's distribution. This hypothesis would suggest that American Samoa would have an anomalously high record in one or more of the unexamined variables among the 4 sites sampled, and would likely share that characteristic with other sites with high proportions of Clade D. We have sampled a consistent set of species at consistent depths and have included the variables most often suggested to be linked to Clade D frequency, including DHW, maximum temperature and, especially, bleaching events (Buddemeier \& Fautin 1993, Goreau \& Hayes 1994, Glynn et al. 2001, Baker et al. 2004). However, these same studies also show that environmental parameters such as light exposure and sediment load affect Clade D's distribution; with the current dataset we cannot rule out the possibility that other factors are more important. Further analysis that covers many collection locations and other coral genera and examines correlations across a wide array of environmental variables is needed to provide this expanded search for relevant environmental variables.

Another related possibility is that we have been looking at the right environmental variables, but not at the right scale. In our regional comparisons, we have been using remotely sensed SST taken on a coarse scale, but detailed knowledge of microhabitat structure, like that observed in American Samoa, may be critical to this kind of analysis.

\section{Cryptic stress tolerance}

Perhaps other undetected, stress-tolerant Symbiodinium exist which are identical to Clade $\mathrm{C}$ using our genetic assay. Garren et al. (2006) identified a subtype of Clade C Symbiodinium in Caribbean Montastrea that associates with hot, turbid areas normally dominated only by Clade D (Garren et al. 2006). This suggests within-clade physiological variation may exist that serves the same function as that ascribed to members of Clade D. The present study found one instance of within-Clade $\mathrm{C}$ variation in Fiji, a population lacking Clade D. However, our genetic assay using cytochrome $b$ almost certainly underestimates withinclade diversity that could identify physiologically distinct Symbiodinium within Clade C. This possibility underscores the need to study the genomic correlates of the high temperature resistance behavior, if only as a rapid means of recognizing newly identified heatresistant strains.

Dispersal limitation

Lack of Clade D Symbiodinium may result from failure of Clade D to migrate to distant Pacific locations. While possible, the hypothesis that Symbiodinium Clade D's range is dispersal-limited seems unlikely because genetic variants of Symbiodinium occur over $1000 \mathrm{~s}$ of $\mathrm{km}$. For example, a single cytochrome $b$ haplotype is present in all 4 regions we studied, suggesting that alleles migrate across the $\sim 8000 \mathrm{~km}$ faster than this locus mutates. In a similar vein, internal transcribe spacer sequences and microsatellite genotypes occur over wide ranges (Baillie et al. 2000, Santos et al. 2004, van Oppen et al. 2005). Because alleles have demonstrably spanned large distances, we find it likely that Clade D has been able to do so as well.

However, there is evidence that suggests that at large scales Symbiodinium are not truly panmictic. Even the relatively slowly evolving cytochrome $b$ shows an allele in multiple individuals in Fiji that was not found elsewhere. One study has found strong structure in Symbiodinium from scleractinian coral over scales of 3000 to $5000 \mathrm{~km}$, but host-symbiont interactions and environmental differentiation may be driving these differences rather than dispersal limitation in Symbiodinium populations (Loh et al. 2001).

\section{Implications for climate change}

Evidence suggests that corals reefs face a daunting risk from rapid climate change (e.g. Hoegh-Guldberg et al. 2007) and that corals might have the capacity to deal with these changes through acclimatization, host evolution or symbiont switching (Baker 2001, Berkelmans \& van Oppen 2006, McClanahan et al. 2007). The fundamental question is whether these adaptive processes will proceed fast enough to match rates of environmental change.

Symbiodinium switching stands out as potentially more rapid and less costly to standing adult coral biomass than natural selection on the coral host. Therefore, the ability to identify areas with physiologically relevant diversity of Symbiodinium can greatly aid conservation planning in the face of climate change.

While a simple explanation of the patterns we document remain elusive, the identification of areas like American Samoa that have high availability of stresstolerant Symbiodinium may be important to policy makers. These areas may better resist coming environmental changes and might serve managers as resilient 
'fortresses of diversity' around which to build their conservation strategy. The establishment of a US National Park in American Samoa may have been a particularly valuable move that allows a substantial area of temperature-resistant reef to be protected from the anthropogenic impacts of sedimentation, overfishing and eutrophication.

Definitively predicting what conditions favor heatresistant Symbiodinium on a more global scale is currently limited both by the local focus of most Symbiodinium genotyping studies and our inability to identify novel heat-resistant strains. To move forward, we will need broader reviews of the environmental correlates to the distribution of known heat-resistant Symbiodinium and a greater understanding of the functional genetic correlates of high temperature resistance in Symbiodinium.

Acknowledgements. The authors acknowledge the assistance of C. Birkeland, D. Barshis, L. Smith, and C. Squair at the University of Hawaii and P. Craig (US National Park Service, American Samoa) for their support in American Samoa; the Palmyra Atoll Research Consortium; the Hawaiian Undersea Research Lab; and the National Park of American Samoa. We also thank the NSF Predoctoral fellowship program, the Woods Institute for the Environment, NOAA and NSF for funding.

\section{LITERATURE CITED}

Baillie BK, Belda-Baillie CA, Maruyama T (2000) Conspecificity and Indo-Pacific distribution of Symbiodinium genotypes (Dinophyceae) from giant clams. J Phycol 36: 1153-1161

Baker AC (2001) Ecosystems: reef corals bleach to survive change. Nature 411:765-766

> Baker AC, Romanski AM (2007) Multiple symbiotic partnerships are common in scleractinian corals, but not in octocorals: Comment on Goulet (2006). Mar Ecol Prog Ser 335: 237-242

Baker AC, Starger CJ, McClanahan TR, Glynn PW (2004) Corals' adaptive response to climate change. Nature 430: 741

Baker C (2003) Flexibility and specificity in coral-algal symbiosis: diversity, ecology, and biogeography of Symbiodinium. Annu Rev Ecol Evol Syst 34:661-689

Berkelmans R, van Oppen MJH (2006) The role of zooxanthellae in the thermal tolerance of corals: a 'nugget of hope' for coral reefs in an era of climate change. Proc R Soc Biol Sci Ser B 273:2305-2312

Bindoff NL, Willebrand J, Artale V, Cazenave A and others (2007) Observations: oceanic climate change and sea level. In: Solomon S, Qin D, Manning M, Chen Z and others (eds) Climate change 2007: the physical science basis. Contribution of Working Group I to the 4th assessment report of the Intergovernmental Panel on Climate Change. Cambridge University Press, Cambridge

Buddemeier RW, Fautin DG (1993) Coral bleaching as an adaptive mechanism: a testable hypothesis. Bioscience 43: 320-326

Chen CA, Lam KK, Nakano Y, Tsai WS (2003) A stable association of the stress-tolerant zooxanthellae, Symbiodinium Clade D, with the low-temperature-tolerant coral, Oulas- trea crispata (Scleractinia: Faviidae) in subtropical nonreefal coral communities. Zool Stud 42:540-550

Fitt WK, Brown BE, Warner ME, Dunne RP (2001) Coral bleaching: interpretation of thermal tolerance limits and thermal thresholds in tropical corals. Coral Reefs 20:51-65

Garren M, Walsh SM, Caccone A, Knowlton N (2006) Patterns of association between Symbiodinium and members of the Montastraea annularis species complex on spatial scales ranging from within colonies to between geographic regions. Coral Reefs 25:503-512

Glynn PW, Mate JL, Baker AC, Calderon MO (2001) Coral bleaching and mortality in Panama and Ecuador during the 1997-1998 El Niño-Southern Oscillation event: spatial/ temporal patterns and comparisons with the 1982-1983 event. Bull Mar Sci 69:79-109

Goreau TJ, Hayes RL (1994) Coral bleaching and ocean hotspots. Ambio 23:176-180

Goulet TL (2006) Most corals may not change their symbionts. Mar Ecol Prog Ser 321:1-7

> Hoegh-Guldberg O (1999) Climate change, coral bleaching and the future of the world's coral reefs. Mar Freshw Res 50:839-866

> Hoegh-Guldberg O, Mumby PJ, Hooten AJ, Steneck RS and others (2007) Coral reefs under rapid climate change and ocean acidification. Science 318:1737-1742

Hughes TP, Baird AH, Bellwood DR, Card M and others (2003) Climate change, human impacts, and the resilience of coral reefs. Science 301:929-933

Jones AM, Berkelmans R, van Oppen MJH, Mieog JC, Sinclair W (2008) A community change in the algal endosymbionts of a scleractinian coral following a natural bleaching event: field evidence of acclimatization. Proc R Soc Biol Sci Ser B 275:1359-1365

> LaJeunesse TC, Bhagooli R, Hidaka M, DeVantier L and others (2004) Closely related Symbiodinium spp. differ in relative dominance in coral reef host communities across environmental, latitudinal and biogeographic gradients. Mar Ecol Prog Ser 284:147-161

LaJeunesse TC, Finney J, Smith R, Oxenford H (2008) Proliferation of an opportunistic Symbiodinium sp. during the 2005 Eastern Caribbean mass coral 'bleaching.' 11th Int Coral Reef Symp, 7-11 July 2008, Fort Lauderdale, FL (Abstract). International Society for Reef Studies, Den Burg

Lien YT, Nakano Y, Plathong S, Fukami H, Wang JT, Chen CA (2007) Occurrence of the putatively heat-tolerant Symbiodinium phylotype D in high-latitudinal outlying coral communities. Coral Reefs 26:35-44

Little AF, van Oppen MJH, Willis BL (2004) Flexibility in algal endosymbioses shapes growth in reef corals. Science 304: 1492-1494

> Loh WKW, Loi T, Carter D, Hoegh-Guldberg O (2001) Genetic variability of the symbiotic dinoflagellates from the wide ranging coral species Seriatopora hystrix and Acropora longicyathus in the Indo-West Pacific. Mar Ecol Prog Ser 222:97-107

McClanahan TR, Muthiga NA, Mangi S (2001) Coral and algal changes after the 1998 coral bleaching: interaction with reef management and herbivores on Kenyan reefs. Coral Reefs 19:380-391

> McClanahan TR, Ateweberhan M, Graham NAJ, Wilson SK, Sebastian CR, Guillaume MMM, Bruggemann JH (2007) Western Indian Ocean coral communities: bleaching responses and susceptibility to extinction. Mar Ecol Prog Ser 337:1-13

Meehl GA, Stocker TF, Collins WD, Friedlingstein P and others (2007) Global climate projections. In: Solomon S, Qin 
D, Manning M, Chen Z and others (eds) Climate change 2007: the physical science basis. Contribution of Working Group I to the 4 th assessment report of the Intergovernmental Panel on Climate Change. Cambridge University Press, Cambridge

Morgan JA, Strong AE, Eakin CM, Arzayus LF and others (2006) NOAA Coral Reef Watch: global satellite-based analysis, monitoring, and alerts of ocean temperature and coral reef bleaching. Ocean Sciences Meeting, 20-24 February 2006, Honolulu, HI (Abstract). International Society for Reef Studies, Den Burg

NOAA (2007) National Climatic Data Center. Available at: www.ncdc.noaa.gov/ao/ncdc.html

Rowan R (2004) Coral bleaching: thermal adaptation in reef coral symbionts. Nature 430:742

Rowan R, Knowlton N, Baker A, Jara J (1997) Landscape ecology of algal symbionts creates variation in episodes of coral bleaching. Nature 388:265-269

Santos SR, Shearer TL, Hannes AR, Coffroth MA (2004) Fine-scale diversity and specificity in the most prevalent lineage of symbiotic dinoflagellates (Symbiodinium, Dinophyceae) of the Caribbean. Mol Ecol 13: 459-469

Smith-Keune C, van Oppen M (2006) Genetic structure of a reef-building coral from thermally distinct environments on the Great Barrier Reef. Coral Reefs 25:493-502

Thornhill DJ, Fitt WK, Schmidt GW (2006a) Highly stable

Editorial responsibility: Charles Birkeland,

Honolulu, Hawaii, USA symbioses among western Atlantic brooding corals. Coral Reefs 25:515-519

Thornhill DJ, LaJeunesse TC, Kemp DW, Fitt WK, Schmidt GW (2006b) Multi-year, seasonal genotypic surveys of coral-algal symbioses reveal prevalent stability or postbleaching reversion. Mar Biol 148:711-722

Toller WW, Rowan R, Knowlton N (2001) Zooxanthellae of the Montastraea annularis species complex: patterns of distribution of four taxa of Symbiodinium on different reefs and across depths. Biol Bull 201:348-359

> Ulstrup KE, Berkelmans R, Ralph PJ, van Oppen MJH (2006) Variation in bleaching sensitivity of two coral species across a latitudinal gradient on the Great Barrier Reef: the role of zooxanthellae. Mar Ecol Prog Ser 314:135-148

van Oppen MJH, Palstra FP, Piquet AMT, Miller DJ (2001) Patterns of coral-dinoflagellate associations in Acropora: significance of local availability and physiology of Symbiodinium strains and host-symbiont selectivity. Proc R Soc Biol Sci Ser B 268:1759-1767

van Oppen MJH, Mahiny AJ, Done TJ (2005) Geographic distribution of zooxanthella types in three coral species on the Great Barrier Reef sampled after the 2002 bleaching event. Coral Reefs 24:482-487

Zhang H, Bhattacharya D, Lin S (2005) Phylogeny of dinoflagellates based on mitochondrial cytochrome $b$ and nuclear small subunit rDNA sequence comparisons. J Phycol 41:411-420

Submitted: May 20, 2008; Accepted: December 2, 2008 Proofs received from author(s): February 24, 2009 